\title{
Association between estimated glomerular filtration rate and clinical outcomes in ischemic stroke patients with high-grade carotid artery stenosis
}

\author{
Chung-Hao Chao ${ }^{\dagger}$, Chia-Lun Wu ${ }^{\dagger}$ and Wen-Yi Huang*
}

\begin{abstract}
Background: Chronic kidney disease has been identified as a risk factor affecting stroke prognosis. High-grade carotid artery stenosis (CAS) is associated with distal hemodynamic compromise. The association between the estimated glomerular filtration rate (eGFR) and ischemic stroke (IS) outcome in patients with high-grade CAS remains unclear. We aimed to investigate the association between eGFR and outcomes of acute IS patients with high-grade CAS.

Methods: From January 1, 2007 to April 30, 2012, we enrolled 372 acute IS patients with high-grade CAS and prospectively observed them for 5 years. The eGFR on admission was assessed using the Modification of Diet in Renal Disease Study equation. Demographic features, vascular risk factors, comorbidities, and outcomes were compared between different eGFR levels.

Results: Among 372 individuals, 76 (20.4\%) had an eGFR < 45, 65 (17.5\%) had an eGFR between 45 and 59, and 231 (62.1\%) had an eGFR $\geq 60 \mathrm{~mL} / \mathrm{min} / 1.73 \mathrm{~m}^{2}$. Compared to other groups, in the eGFR $<45 \mathrm{~mL} / \mathrm{min} / 1.73 \mathrm{~m}^{2}$ group, the prevalence rates of hypertension, diabetes mellitus, coronary artery disease, congestive heart failure, valvular heart disease, and gout were significantly higher $(P=0.013, P=0.030, P=0.001, P<0.001, P=0.043$, and $P<0.001$, respectively). Patients with eGFR $<45 \mathrm{~mL} / \mathrm{min} / 1.73 \mathrm{~m}^{2}$ demonstrated lower hemoglobin and total cholesterol levels compared with other groups $(P<0.001$ and $P=0.048)$. The blood potassium and uric acid levels were significantly higher in patients with eGFR $<45 \mathrm{~mL} / \mathrm{min} / 1.73 \mathrm{~m}^{2}(P<0.001$ and $P<0.001)$. The multivariate Cox proportional hazards model indicated that eGFR $<45 \mathrm{~mL} / \mathrm{min} / 1.73 \mathrm{~m}^{2}$ was a significant risk factor for 5-year all-cause mortality in IS patients with high-grade CAS after adjusting for these variables (hazard ratio $=2.05 ; 95 \% \mathrm{Cl}=1.31-3.21 ; P=0.002$ ). Conclusions: eGFR $<45 \mathrm{~mL} / \mathrm{min} / 1.73 \mathrm{~m}^{2}$ was associated with an increased risk of 5-year all-cause mortality in acute IS patients with high-grade CAS. Whether aggressive treatment of chronic kidney disease in IS patients with highgrade CAS can improve stroke outcomes should be confirmed in future studies.
\end{abstract}

Keywords: Ischemic stroke, Carotid artery stenosis, Glomerular filtration rate, Mortality, Outcome

\footnotetext{
* Correspondence: wenyihuang2003@yahoo.com.tw

${ }^{\dagger}$ Chung-Hao Chao and Chia-Lun Wu contributed equally to this work Department of Neurology, Chang Gung University, College of Medicine, Chang Gung Memorial Hospital, Keelung branch, No.222, Mai-Jin Road, Keelung 204, Taiwan
}

(c) The Author(s). 2021 Open Access This article is licensed under a Creative Commons Attribution 4.0 International License, which permits use, sharing, adaptation, distribution and reproduction in any medium or format, as long as you give appropriate credit to the original author(s) and the source, provide a link to the Creative Commons licence, and indicate if changes were made. The images or other third party material in this article are included in the article's Creative Commons licence, unless indicated otherwise in a credit line to the material. If material is not included in the article's Creative Commons licence and your intended use is not permitted by statutory regulation or exceeds the permitted use, you will need to obtain permission directly from the copyright holder. To view a copy of this licence, visit http://creativecommons.org/licenses/by/4.0/ The Creative Commons Public Domain Dedication waiver (http://creativecommons.org/publicdomain/zero/1.0/) applies to the data made available in this article, unless otherwise stated in a credit line to the data. 


\section{Background}

Carotid artery stenosis (CAS) is a well-recognized cause of cerebral ischemia, and more severe luminal stenosis is associated with distal hemodynamic compromise [1]. Chronic kidney disease (CKD) has been identified as a novel risk factor affecting stroke prognosis, and the estimated glomerular filtration rate (eGFR) is one of the common parameters representing the renal function [26]. Although CKD is generally regarded as a strong predictor of mortality and poor outcome in patients with acute stroke [5], the findings of previous studies on the association between eGFR and outcome of ischemic stroke (IS) are inconsistent. Some studies indicate that a reduced eGFR is associated with a higher mortality rate in patients with IS $[3,5,7]$, whereas some other studies suggest that a reduced or highly elevated eGFR is associated with a higher mortality rate in patients with IS $[2,4]$.

Patients with severe CAS have a higher risk of stroke and mortality [8], and carotid artery revascularization is capable of reducing the stroke risk $[9,10]$. Patients with CKD are at increased risk of cardiovascular disease and the progression of atherosclerosis [11, 12]. As atherosclerosis is a systemic condition and the prevalence of severe CAS increases with the prevalence of coronary artery stenosis [13], it would be important to understand the association between eGFR and stroke outcome in patients with high-grade CAS. To our knowledge, the association between the level of eGFR and stroke outcome in patients with acute IS has not been assessed specifically in patients with high-grade CAS ( $\geq 70 \%)$ [14].

As a result, the aims of this study were to investigate: (1) the clinical characteristics of acute IS patients with high-grade CAS, comparing patients with different ranges of eGFR and (2) the association between the eGFR level and 5-year outcomes in acute IS patients with high-grade CAS.

\section{Methods}

\section{Ethical standards}

This clinical study followed the Declaration of Helsinki and was approved by the Medical Ethics Committee of Chang Gung Memorial Hospital (CGMH), Taipei, Taiwan (IRB 201800689B0). As this was an observational study without active intervention, and all subjects were diagnosed, treated and followed as clinical routines, the Medical Ethics Committee of CGMH, Taipei, Taiwan waived the requirement for written informed consent.

\section{Study population}

All study patients with acute first-ever IS and high-grade CAS were recruited from the Stroke Unit of the Department of Neurology in Keelung CGMH from January 1, 2007 to April 30, 2012. The diagnosis of acute IS was made in accordance with the World Health Organization criteria, and was confirmed by brain magnetic resonance imaging or computed tomography (CT) scans [15]. The definition of high-grade CAS was $\geq 70 \%$ stenosis at the carotid artery [14]. To evaluate the severity of CAS, carotid duplex ultrasound was performed within 7 days after stroke onset. Duplex examinations were performed using Philips EnVisor C (Philips Medical Systems, Nederland B.V.) with a $7-\mathrm{MHz}$ linear-array probe by an experienced technical assistant who was supervised by 2 of the authors. The diameter of the residual lumen at most stenotic portion (d) and the external diameter of the artery at the same level (D) were measured, and the degree of stenosis was calculated using the following equation: percentage of stenosis $=(D-d)$ 100/D $[14,16]$.

If the ultrasound results revealed $\geq 70 \%$ stenosis at the carotid artery, brain magnetic resonance angiography was arranged to confirm the CAS and evaluate the location and volume of the infarction. We only recruited patients with high-grade CAS with a degree of stenosis ranging from 70 to $100 \%$ [14], and acute stroke symptoms can be correlated with the vascular territory of the carotid artery with CAS. The exclusion criteria were as follows: (1) the location of infarction cannot be correlated with the vascular territory of high-grade CAS; (2) patients received revascularization treatments; (3) patients with previous IS, cerebral hemorrhage, or stroke of uncertain causes; and (4) patients with severe medical diseases, such as malignancy, liver cirrhosis, or end-stage renal disease with hemodialysis or peritoneal dialysis.

The renal function of the recruited patients with acute IS and high-grade CAS was assessed using the Modification of Diet in Renal Disease Study equation for eGFR: eGFR $\left(\mathrm{mL} / \mathrm{min} / 1.73 \mathrm{~m}^{2}\right)=186 \times($ serum creatinine $[\mathrm{mg} /$ $\mathrm{dL}])^{-1.154} \times(\text { age [years] })^{-0.203} \times(0.742$ if female $)$ [17]

All recruited patients were stratified by eGFR into the following three groups for statistical analysis: (1) eGFR $<45 \mathrm{~mL} / \mathrm{min} / 1.73 \mathrm{~m}^{2}$; (2) eGFR $45-59 \mathrm{~mL} / \mathrm{min} / 1.73 \mathrm{~m}^{2}$; and (3) eGFR $\geq 60 \mathrm{~mL} / \mathrm{min} / 1.73 \mathrm{~m}^{2}$. We grouped the recruited patients according to the stages of chronic kidney disease [18]. eGFR $\geq 60 \mathrm{~mL} / \mathrm{min} / 1.73 \mathrm{~m}^{2}$ indicated CKD stage 1 (normal kidney function) and stage 2 (mild loss of kidney function); eGFR $45-59 \mathrm{~mL} / \mathrm{min} / 1.73 \mathrm{~m}^{2}$ indicated CKD stage 3a (mild to moderate loss of kidney function); eGFR $<45 \mathrm{~mL} / \mathrm{min} / 1.73 \mathrm{~m}^{2}$ indicated CKD stage $3 \mathrm{~b}$ (moderate to severe loss of kidney function), stage 4 (severe loss of kidney function), and stage 5 (kidney failure).

\section{Clinical assessments}

Comorbidities and vascular risk factors such as hypertension, diabetes mellitus (DM), hyperlipidemia, smoking, atrial fibrillation (AF), valvular heart disease, peripheral arterial diseases, and coronary artery disease (CAD), were identified after an in-depth review of the 
medical records. Hypertension was diagnosed as systolic blood pressure $>160 \mathrm{mmHg}$ and/or diastolic blood pressure $>95 \mathrm{mmHg}$ on two different occasions with the first measurement within 2 days after stroke onset and the second measurement taken more than 5 days after the stroke, or known hypertension was diagnosed by a clinician $[19,20]$. DM was identified in patients with fasting plasma glucose $\geq 7.0 \mathrm{mmol} / \mathrm{L}$ or a 2 -h value in the oral glucose tolerance test $\geq 11.1 \mathrm{mmol} / \mathrm{L}$ or a random plasma glucose concentration $\geq 11.1 \mathrm{mmol} / \mathrm{L}$ in the presence of symptoms or patients with previously treated DM [21]. AF was identified by ECG and/or 24-h ECG monitoring. Cigarette smoking was identified as a current smoker or a smoker with cessation less than 5 years ago. Laboratory assessments, such as complete blood cell count, biochemistry studies, lipid level, glycohemoglobin, coagulation testing, 12-lead electrocardiography, and transthoracic echocardiography, were performed within 1 week after acute stroke onset. The clinical IS subtypes of the Oxfordshire Community Stroke Project classification [22] and the scores of the National Institutes of Health Stroke scale, Modified Rankin scale [23], and Barthel index were recorded.

\section{Follow-up}

The timings of follow-up were at the first and third months after the initial assessment of acute ischemic stroke and then every 3 months. All recruited patients were followed up for 5 years after acute ischemic stroke. The follow-up period was from January 1, 2007 to April
30, 2017. The primary end points included 5-year mortality, stroke-related death, or stroke recurrence. Every cause of death was reviewed. New major medical problems, such as death, recurrent IS, cerebral hemorrhage, cancer, head injury, and reason for rehospitalization, were recorded.

\section{Statistical analysis}

Continuous variables were expressed as medians (interquartile ranges) as they were not normally distributed. Categorical variables were expressed as a number (percentage) [24]. The clinical characteristics of the patients in the different eGFR groups were analyzed using descriptive statistics. The Kruskal-Wallis or chi-square test was used to assess the group differences [24]. Kaplan-Meier survival analysis was used to estimate the cumulative overall survival for patients with different eGFR levels, and the log-rank test was used to assess the group differences [25]. The Cox proportional hazards model was used to determine the significance of each variable in predicting 5-year mortality. A univariate Cox model was used initially to measure the hazard ratio of all previously identified variables for mortality. Then, a backward, stepwise multivariate Cox regression model was used to identify the risk factors for 5-year mortality [25]. All statistical analyses were performed using IBM SPSS statistics 19 for Windows.

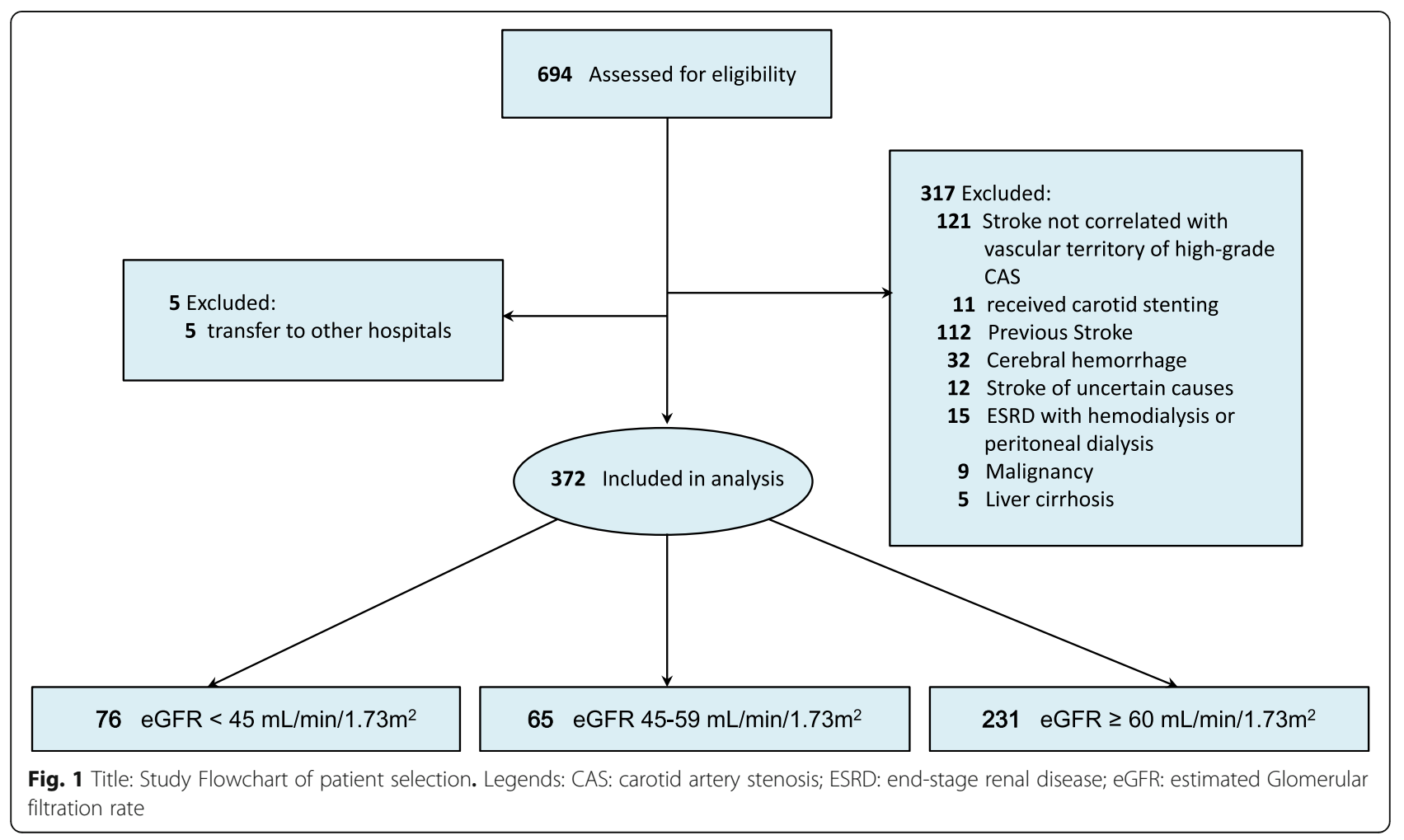




\section{Results}

Demographic characteristics among IS patients with highgrade CAS

Between January 1, 2007 and April 30, 2012, 694 acute IS patients with high-grade CAS were identified. Among these patients, 322 patients were excluded because they did not fulfill the inclusion criteria. Eleven patients received carotid artery stenting, and these patients were excluded from the study. Finally, a total of 372 acute IS patients with high-grade CAS were enrolled in this study (Fig. 1). The patients were then categorized by the eGFR value as follows: eGFR $<45 \mathrm{~mL} / \mathrm{min} / 1.73 \mathrm{~m}^{2}$ (76 subjects); $45-59 \mathrm{~mL} / \mathrm{min} / 1.73 \mathrm{~m}^{2}$ (65 subjects); and $\geq 60$ $\mathrm{mL} / \mathrm{min} / 1.73 \mathrm{~m}^{2}$ (231 subjects). The median age was 73 (63-81) years. Patient characteristics are presented in Table 1. Compared to other groups, in the eGFR $<45$ $\mathrm{mL} / \mathrm{min} / 1.73 \mathrm{~m}^{2}$ group, the prevalence rates of hypertension, DM, CAD, congestive heart failure, valvular

Table 1 Demographic features of ischemic stroke patients with high-grade carotid artery stenosis

\begin{tabular}{|c|c|c|c|c|}
\hline & \multicolumn{3}{|c|}{ eGFR $\left(\mathrm{mL} / \mathrm{min} / 1.73 \mathrm{~m}^{2}\right)$} & \multirow[b]{2}{*}{$P$} \\
\hline & $\begin{array}{l}<45 \\
(n=76)\end{array}$ & $\begin{array}{l}45-59 \\
(n=65)\end{array}$ & $\begin{array}{l}\geq 60 \\
(n=231)\end{array}$ & \\
\hline Age (years) & $77(71-82)$ & $75(70-81)$ & $70(61-79)$ & $<0.001^{*}$ \\
\hline Male (\%) & $48(63.2)$ & $44(67.7)$ & $181(78.4)$ & $0.018+$ \\
\hline \multicolumn{5}{|l|}{ Risk factors } \\
\hline Hypertension (\%) & $72(94.7)$ & $53(81.5)$ & $186(80.5)$ & $0.013+$ \\
\hline Diabetes mellitus (\%) & $46(60.5)$ & $29(44.6)$ & $100(43.3)$ & $0.030+$ \\
\hline Smoking (\%) & $45(59.2)$ & $40(61.5)$ & $161(69.7)$ & 0.170 \\
\hline Hyperlipidemia (\%) & $43(56.6)$ & $43(66.2)$ & $143(61.9)$ & 0.500 \\
\hline Atrial fibrillation (\%) & $18(24.0)$ & $11(16.9)$ & $35(15.2)$ & 0.211 \\
\hline CAD (\%) & $26(34.2)$ & $15(23.1)$ & $34(14.7)$ & $0.001+$ \\
\hline CHF (\%) & $20(26.3)$ & $8(12.3)$ & $13(5.6)$ & $<0.001 \dagger$ \\
\hline Valvular heart disease (\%) & $4(5.3)$ & $3(4.6)$ & $2(0.9)$ & $0.043+$ \\
\hline Peripheral vascular disease (\%) & $3(3.9)$ & $2(3.1)$ & $4(1.7)$ & 0.513 \\
\hline Gout (\%) & $34(44.7)$ & $17(26.2)$ & $28(12.1)$ & $<0.001 \dagger$ \\
\hline \multicolumn{5}{|l|}{ Clinical syndromes } \\
\hline $\mathrm{TACl}(\%)$ & $13(17.1)$ & $14(21.5)$ & $44(19.0)$ & 0.800 \\
\hline PACl (\%) & $31(40.8)$ & $25(38.5)$ & $87(37.7)$ & 0.889 \\
\hline LACI (\%) & $28(36.8)$ & $20(30.8)$ & $80(34.8)$ & 0.743 \\
\hline \multicolumn{5}{|l|}{ Laboratory data } \\
\hline Hemoglobin (mmol/L) & $7.63(6.83-8.32)$ & $8.32(7.63-9)$ & $8.63(7.88-9.37)$ & $<0.001^{*}$ \\
\hline WBC $\left(10^{9} / \mathrm{L}\right)$ & $7.60(6.20-9.78)$ & $7.60(5.95-9.45)$ & $7.90(6.30-9.50)$ & 0.670 \\
\hline Platelet $\left(10^{9} / \mathrm{L}\right)$ & $204(167-268)$ & $193(160-261)$ & $208(175-255)$ & 0.604 \\
\hline Glycohemoglobin (\%) & $6.3(5.8-7.3)$ & $6.1(5.8-7.0)$ & $6.0(5.7-6.9)$ & 0.279 \\
\hline hs-CRP (nmol/L) & $57.1(27.6-160)$ & $47.2(28.6-91.4)$ & $42.9(21.0-85.7)$ & 0.081 \\
\hline Total cholesterol (mmol/L) & $4.60(3.62-5.48)$ & $4.81(4.27-6)$ & $4.89(4.29-5.56)$ & $0.048^{*}$ \\
\hline $\mathrm{Na}(\mathrm{mmol} / \mathrm{L})$ & $138(136-140)$ & $138(136-140)$ & $138(136-140)$ & 0.710 \\
\hline $\mathrm{K}(\mathrm{mmol} / \mathrm{L})$ & $4.1(3.8-4.6)$ & $3.9(3.6-4.2)$ & $3.9(3.6-4.1)$ & $<0.001^{*}$ \\
\hline Uric acid (mmol/L) & $0.41(0.36-0.48)$ & $0.35(0.29-0.40)$ & $0.34(0.28-0.39)$ & $<0.001^{*}$ \\
\hline \multicolumn{5}{|l|}{ Antithrombotic treatment } \\
\hline Aspirin (\%) & $41(53.9)$ & $47(72.3)$ & $159(68.8)$ & $0.032+$ \\
\hline Clopidogrel (\%) & $26(34.2)$ & $11(16.9)$ & $54(23.4)$ & $0.048+$ \\
\hline Anticoagulant (\%) & $9(11.8)$ & $9(13.8)$ & $30(13.0)$ & 0.938 \\
\hline None (\%) & $3(3.9)$ & $2(3.1)$ & $2(0.9)$ & $0.032 \dagger$ \\
\hline
\end{tabular}


heart disease, and gout were significantly higher $(P=$ 0.013, $P=0.030, P=0.001, P<0.001, P=0.043$, and $P<$ 0.001 , respectively).

\section{Clinical course among IS patients with high-grade CAS}

Patient characteristics and clinical course are summarized in Table 2. The mean length of acute ward stay and the occurrences of initial impaired consciousness, stroke evolution, in-hospital complications, stroke recurrence, and stroke-related death did not differ between the groups with different eGFRs in IS patients with high-grade CAS. However, the 5-year all-cause mortality rate was significantly higher in the eGFR $<45 \mathrm{~mL} / \mathrm{min} /$ $1.73 \mathrm{~m}^{2}$ group compared with other groups $(P=0.001)$.

\section{Survival analysis of mortality in IS patients with high- grade CAS}

At the end of the 5-year observation period, 98 patients had died $(98 / 372=26.3 \%)$, including $32(42.1 \%)$ patients with eGFR $<45 \mathrm{~mL} / \mathrm{min} / 1.73 \mathrm{~m}^{2}, 18$ (27.7\%) patients with eGFR between 45 and $59 \mathrm{~mL} / \mathrm{min} / 1.73 \mathrm{~m}^{2}$, and 48 (20.8\%) patients with eGFR $\geq 60 \mathrm{~mL} / \mathrm{min} / 1.73 \mathrm{~m}^{2}$. The cause of patient death in the group with eGFR $<45 \mathrm{~mL} /$ $\mathrm{min} / 1.73 \mathrm{~m}^{2}$ included acute stroke-related (2 patients), pneumonia and respiratory failure (7 patients), septic shock ( 9 patients), cardiovascular disease (7 patients), out-of-hospital cardiac arrest (2 patients), end-stage renal disease ( 2 patients), recurrent large infarction with brainstem compression (1 patient), and unknown causes (2 patients). The Kaplan-Meier survival analysis showed that the eGFR $<45 \mathrm{~mL} / \mathrm{min} / 1.73 \mathrm{~m}^{2}$ group had a higher mortality rate than the other groups (log-rank test, $P<$ 0.001), as shown in Fig. 2.

\section{Determinants of mortality in IS patients with high-grade CAS}

The univariate Cox regression indicated that older age, eGFR $<45 \mathrm{~mL} / \mathrm{min} / 1.73 \mathrm{~m}^{2}$, lower lipid level, CAD, AF, congestive heart failure, stroke presenting as total anterior circulation infarcts, pneumonia, and gastrointestinal

Table 2 Clinical courses of ischemic stroke patients with high-grade carotid artery stenosis

\begin{tabular}{|c|c|c|c|c|}
\hline & \multicolumn{3}{|c|}{ eGFR $\left(\mathrm{mL} / \mathrm{min} / 1.73 \mathrm{~m}^{2}\right)$} & \multirow[b]{2}{*}{$P$ value } \\
\hline & $\begin{array}{l}<45 \\
(n=76)\end{array}$ & $\begin{array}{l}45-59 \\
(n=65) \\
\end{array}$ & $\begin{array}{l}\geq 60 \\
(n=231)\end{array}$ & \\
\hline Mean length of stay in the acute medicine ward (days) & $11(7-16)$ & $12(8-18)$ & $11(7-17)$ & 0.592 \\
\hline Initial impaired consciousness (\%) & $16(21.1)$ & $16(24.6)$ & $50(21.6)$ & 0.854 \\
\hline \multicolumn{5}{|l|}{ Course of acute stroke stage } \\
\hline In evolution (\%) & $16(21.1)$ & $11(16.9)$ & $41(17.7)$ & 0.773 \\
\hline \multicolumn{5}{|l|}{ Complications } \\
\hline Pneumonia (\%) & $9(11.8)$ & $12(18.8)$ & $29(12.6)$ & 0.393 \\
\hline Gastrointestinal bleeding (\%) & $18(23.7)$ & $10(15.6)$ & $38(16.5)$ & 0.323 \\
\hline Urinary tract infection (\%) & $12(15.8)$ & $9(14.1)$ & $23(10.0)$ & 0.330 \\
\hline \multicolumn{5}{|l|}{ Glasgow coma scale score } \\
\hline Upon admission & $15(15-15)$ & $15(15-15)$ & $15(15-15)$ & 0.842 \\
\hline Upon discharge & $15(15-15)$ & $15(14-15)$ & $15(15-15)$ & 0.777 \\
\hline \multicolumn{5}{|l|}{ National Institutes of Health Stroke Scale score } \\
\hline Upon admission & $6(3-10)$ & $6(3-12)$ & $5(3-9)$ & 0.399 \\
\hline Upon discharge & $6(2 .-10)$ & $7(3-11)$ & $5(2-9)$ & 0.198 \\
\hline \multicolumn{5}{|l|}{ Modified Rankin Scale score } \\
\hline Upon admission & $3(2-4)$ & $3(2-4)$ & $3(2-4)$ & 0.198 \\
\hline Upon discharge & $3(2-4)$ & $3(2-4)$ & $2(1-4)$ & 0.093 \\
\hline \multicolumn{5}{|l|}{ Barthel index score } \\
\hline Upon admission & $60(40-80)$ & $70(35-80)$ & $75(40-90)$ & 0.220 \\
\hline Upon discharge & $70(40-90)$ & $65(30-90)$ & $80(40-95)$ & 0.058 \\
\hline Stroke recurrence (\%) & $18(23.7)$ & $22(33.8)$ & $71(30.7)$ & 0.375 \\
\hline Stroke-related death (\%) & $3(3.9)$ & $2(3.1)$ & $4(1.7)$ & 0.712 \\
\hline Death (\%) & $32(42.1)$ & 18 (27.7) & $48(20.8)$ & $0.001+$ \\
\hline
\end{tabular}

eGFR indicates estimated Glomerular filtration rate

Data are presented as median (interquartile range) or absolute numbers (percentage)

${ }^{*} P<0.05$, Kruskal-Wallis test; $+P<0.05$, Chi-square test 


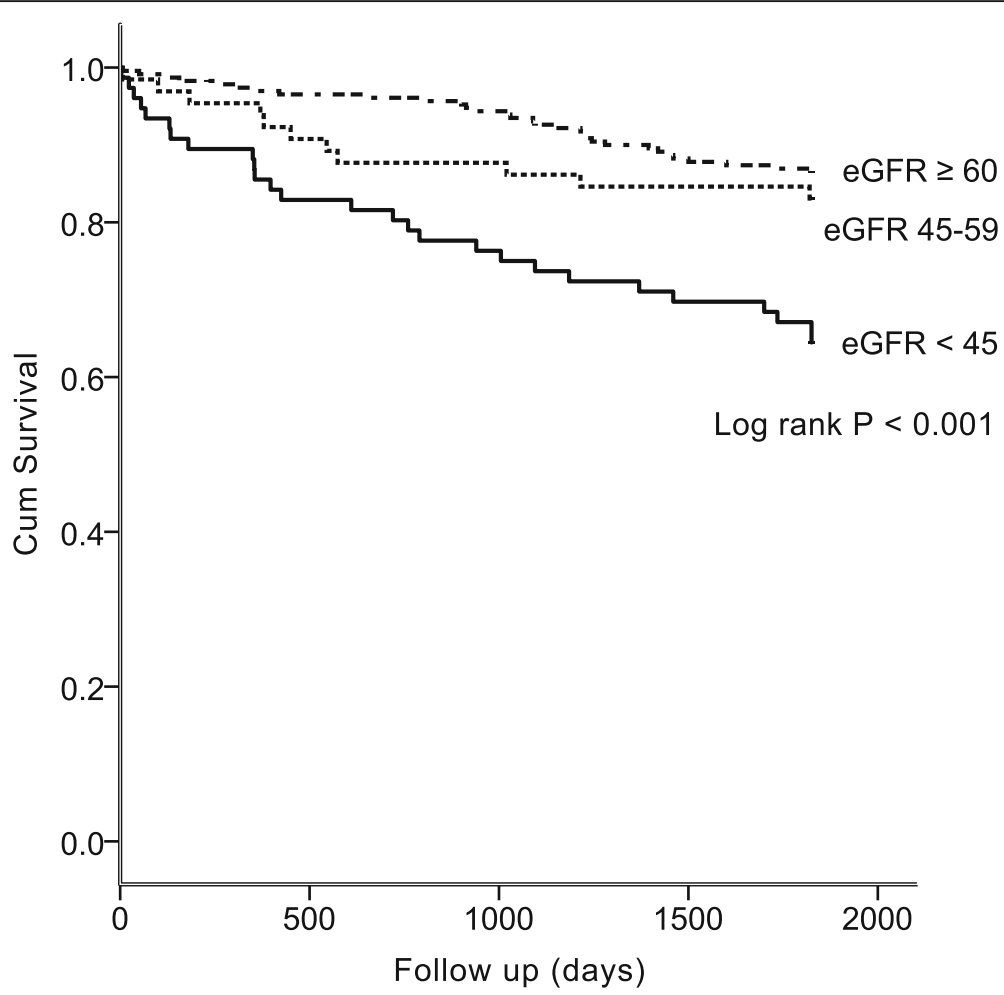

Fig. 2 Title: Kaplan-Meier estimates of patient survival during the 5 -year study period Legends: Log-rank test, $P<0.001$. eGFR: estimated Glomerular filtration rate

bleeding were potential risk factors $(P<0.1)$ for 5 -year all-cause mortality. These variables $(P<0.1)$ were then entered into the multivariate Cox regression analysis. The multivariate Cox proportional hazards model indicated that eGFR $<45 \mathrm{~mL} / \mathrm{min} / 1.73 \mathrm{~m}^{2}$ was a significant risk factor for 5-year all-cause mortality in IS patients with high-grade CAS after adjusting for these variables $(\mathrm{HR}=2.05 ; 95 \% \mathrm{CI}=1.31-3.21 ; P=0.002)$ (Table 3$)$.

\section{Discussion}

As noted in previous limited studies about the influence of eGFR level on high-grade CAS, it is important to identify the association between eGFR and clinical outcomes in IS patients with high-grade CAS. We demonstrated that a lower eGFR, especially eGFR $<45 \mathrm{~mL} /$ $\mathrm{min} / 1.73 \mathrm{~m}^{2}$, was associated with 5 -year all-cause mortality. This association remained significant even after adjusting for the established clinical predictors of adverse outcomes.

Previous studies have revealed that impaired eGFR is independently associated with an increased risk of allcause mortality in the overall population [26, 27] and IS patients [28]. Of the IS patients with high-grade CAS whose eGFR $<45 \mathrm{~mL} / \mathrm{min} / 1.73 \mathrm{~m}^{2}$ died, only approximately $6 \%$ died from acute stroke, which may be explained by the fact that stroke severity was not significantly different between the groups with different eGFRs. A large number (50\%) of IS patients with highgrade CAS whose eGFR $<45 \mathrm{~mL} / \mathrm{min} / 1.73 \mathrm{~m}^{2}$ died from pneumonia with respiratory failure or septic shock.

The classification of CKD based on the level of eGFR had been defined by the guideline from Kidney Disease: Improving Global Outcomes [18]. Previous studies suggested that the impairment of normal innate and adaptive immune systems in CKD predisposes patients to an increased risk of infection, and infection is one of the leading causes of mortality in patients with CKD [29]. Approximately $28 \%$ of the patients with eGFR $<45 \mathrm{~mL} /$ $\mathrm{min} / 1.73 \mathrm{~m}^{2}$ died from cardiovascular disease or out-ofhospital cardiac arrest. CKD is an independent risk factor for cardiovascular disease, and the risk of cardiovascular mortality increases when the condition of CKD deteriorates [30].

Our study revealed that older age, hypertension, DM, $\mathrm{CAD}$ and hyperuricemia occurred more frequently in patients with reduced eGFR $<45 \mathrm{~mL} / \mathrm{min} / 1.73 \mathrm{~m}^{2}$, which was consistent with a previous study [26, 28]. Older age [31], hypertension [32], DM [33], and gout [34] are known risk factors for CKD. The risk of CAD increases as the severity of CKD increases, despite adjustment for traditional cardiovascular risk factors [35]. It is not surprising that the level of hemoglobin was lower in 
Table 3 Cox regression analysis of patient survival during the 5-year study period

\begin{tabular}{|c|c|c|c|c|}
\hline & \multicolumn{2}{|c|}{ Univariate Cox regression } & \multicolumn{2}{|c|}{ Multivariate Cox regression } \\
\hline & $\mathrm{HR}(95 \% \mathrm{Cl})$ & $P$ value & $\mathrm{HR}(95 \% \mathrm{Cl})$ & $P$ value \\
\hline Age & $1.06(1.03-1.08)$ & $<0.001^{*}$ & $1.03(1.01-1.05)$ & $0.001+$ \\
\hline Male & $0.74(0.45-1.23)$ & 0.242 & & \\
\hline $\mathrm{eGFR}<45 \mathrm{~mL} / \mathrm{min} / 1.73 \mathrm{~m}^{2}$ & $2.90(1.79-4.70)$ & $<0.001^{*}$ & $2.05(1.31-3.21)$ & $0.002 \dagger$ \\
\hline Hypertension & $1.37(0.68-2.76)$ & 0.379 & & \\
\hline Diabetes mellitus & $0.90(0.56-1.44)$ & 0.651 & & \\
\hline Hyperlipidemia & $0.52(0.32-0.83)$ & $0.007^{*}$ & & \\
\hline Coronary artery disease & $2.54(1.55-4.14)$ & $<0.001^{*}$ & $1.98(1.28-3.06)$ & $0.002 \dagger$ \\
\hline Atrial fibrillation & $1.89(1.10-3.23)$ & $0.021^{*}$ & & \\
\hline Congestive heart failure & $2.72(1.56-4.76)$ & $<0.001^{*}$ & & \\
\hline Smoking & $1.01(0.61-1.66)$ & 0.980 & & \\
\hline $\mathrm{TACl}$ & $3.34(2.06-5.42)$ & $<0.001^{*}$ & $2.72(1.75-4.25)$ & $<0.001 \dagger$ \\
\hline Pneumonia & $2.54(1.47-4.40)$ & $0.001^{*}$ & & \\
\hline Gastrointestinal bleeding & $2.36(1.41-3.95)$ & $0.001^{*}$ & $1.73(1.10-2.71)$ & $0.018+$ \\
\hline
\end{tabular}

$\mathrm{HR}$ indicates hazard ratio; $\mathrm{Cl}$ confidence interval; $T A C l$ total anterior circulation infarcts

${ }^{*} P<0.1$ for the univariate Cox regression, and $+P<0.05$ for the multivariate Cox regression

patients with reduced eGFR $<45 \mathrm{~mL} / \mathrm{min} / 1.73 \mathrm{~m}^{2}$. Decreased erythropoietin production, nutrition deficiency, shortened red blood cell survival and increased iron losses might contribute to the lower hemoglobin levels in patients with reduced eGFR [36].

Recruited patients did not receive revascularization treatment due to the following reasons: (1) some patients hesitated about carotid angioplasty and stenting given concerns about potential complications of the procedure; (2) the vascular surgeons in our hospital were not subspecialized in carotid endarterectomy; (3) some patients could not tolerate long-term dual antiplatelet therapy, such as active peptic ulcers; and (4) some patients had moderate to severe CKD, and they worried that the contrast medium may worsen their renal function.

This study has several limitations. First, we did not identify the pathogenesis of CKD with eGFR $<45 \mathrm{~mL} /$ $\min / 1.73 \mathrm{~m}^{2}$ in all of the recruited subjects, and different etiologies of CKD may lead to different outcomes [18]. Second, this is an observational study about the association between eGFR levels and 5-year mortality in IS patients with high-grade CAS. Therefore, we cannot conclude that aggressive treatment of CKD in IS patients with high-grade CAS can improve stroke outcomes. However, aggressive control of common risk factors for CKD may provide benefit for reducing long-term mortality in IS patients with high-grade CAS. Third, we did not identify the etiologies of high-grade CAS. Thus, it was difficult to differentiate patients with cardiogenic embolic stroke from those with stroke related to stenosis or occlusion in carotid arteries. Different mechanisms of IS may lead to different outcomes. Fourth, this study was performed in one center, and the sample size was relatively small and may not represent the whole disease group. Fifth, we did not analyze the conditions of other intracranial large arteries and possible collateral flows. The collateral status may be associated with the infarct volume and may influence the stroke outcome [37].

\section{Conclusions}

In acute IS patients with high-grade CAS, eGFR $<45$ $\mathrm{mL} / \mathrm{min} / 1.73 \mathrm{~m}^{2}$ is associated with an increased risk of 5-year all-cause mortality. Whether aggressive treatment of CKD in IS patients with high-grade CAS can improve stroke outcomes should be confirmed in future studies.

\section{Abbreviations}

CAS: Carotid artery stenosis; CKD: Chronic kidney disease; eGFR: Estimated glomerular filtration rate; IS: Ischemic stroke; CGMH: Chang Gung Memorial Hospital; CT: Computed tomography; DM: Diabetes mellitus; AF: Atrial fibrillation; CAD: Coronary artery disease

\section{Acknowledgments}

We gratefully acknowledge Habibzadeh F, Clark TG, Bradburn MJ, Love SB, Altman DG, Ranganathan P, Pramesh CS, and Aggarwal R for the methods of statistical analysis and have cited their manuscripts in references [13-15]. We also gratefully acknowledge all staff of the department of neurology and nephrology in $\mathrm{CGMH}$.

\section{Authors' contributions}

CHC, CLW, and WYH contributed to the conception, design of the work, and drafted the paper. WYH contributed to acquisition, interpretation and critically revised manuscript. All authors critically revised the manuscript for important intellectual content, approved the final version submitted and agreed to be accountable for all aspects of the work.

\section{Funding}

This work was supported by CGMH, grant number: CMRPG2J0121 and CMRP G2K0031. 


\section{Availability of data and materials}

The dataset analyzed during the current study are available from the corresponding author on reasonable request.

\section{Declarations}

\section{Ethics approval and consent to participate}

This clinical study followed the Declaration of Helsinki and was approved by the Medical Ethics Committee of Chang Gung Memorial Hospital (CGMH), Taipei, Taiwan (IRB 201800689B0). As this was an observational study without active intervention, and all subjects were diagnosed, treated and followed as clinical routines, the Medical Ethics Committee of CGMH, Taipei, Taiwan had approved that the requirement for the written informed consent was waived.

\section{Consent for publication}

Not applicable.

\section{Competing interests}

The authors declare that they have no competing interests.

Received: 14 December 2020 Accepted: 10 March 2021 Published online: 19 March 2021

\section{References}

1. Banerjee C, Chimowitz MI. Stroke caused by atherosclerosis of the major intracranial arteries. Circ Res. 2017;120(3):502-13. https://doi.org/10.1161/ CIRCRESAHA.116.308441.

2. Mostofsky E, Wellenius GA, Noheria A, Levitan EB, Burger MR, Schlaug G, Mittleman MA. Renal function predicts survival in patients with acute ischemic stroke. Cerebrovasc Dis. 2009;28(1):88-94. https://doi.org/10.1159/ 000219302.

3. Tsagalis G, Akrivos T, Alevizaki M, Manios E, Stamatellopoulos K, Laggouranis A, et al. Renal dysfunction in acute stroke: an independent predictor of long-term all combined vascular events and overall mortality. Nephrol Dial Transplant. 2009;24(1):194-200.

4. Widhi Nugroho A, Arima H, Miyazawa I, Fujii T, Miyamatsu N, Sugimoto Y, Nagata S, Komori M, Takashima N, Kita Y, Miura K, Nozaki K. The association between glomerular filtration rate estimated on admission and acute stroke outcome: the Shiga stroke registry. J Atheroscler Thromb. 2018;25(7):570-9. https://doi.org/10.5551/jat.42812.

5. Yahalom G, Schwartz R, Schwammenthal Y, Merzeliak O, Toashi M, Orion D, Sela BA, Tanne D. Chronic kidney disease and clinical outcome in patients with acute stroke. Stroke. 2009;40(4):1296-303. https://doi.org/10.1161/ STROKEAHA.108.520882.

6. Yang J, Arima H, Zhou J, Zhao Y, Li Q, Wu G, Zhang Y. Effects of low estimated glomerular filtration rate on outcomes after stroke: a hospitalbased stroke registry in China. Eur J Neurol. 2014;21(8):1143-5. https://doi. org/10.1111/ene.12311.

7. Wang X, Wang Y, Wang C, Zhao X, Xian Y, Wang D, Liu L, Luo Y, Liu G, Wang $Y$. Association between estimated glomerular filtration rate and clinical outcomes in patients with acute ischaemic stroke: results from China National Stroke Registry. Age Ageing. 2014;43(6):839-45. https://doi.org/10.1 093/ageing/afu090.

8. Marzewski DJ, Furlan AJ, St Louis P, Little JR, Modic MT, Williams G. Intracranial internal carotid artery stenosis: Longterm prognosis. Stroke. 1982;13(6):821-4. https://doi.org/10.1161/01.STR.13.6.821.

9. Lanzino G, Rabinstein AA, Brown RD Jr. Treatment of carotid artery stenosis: medical therapy, surgery, or stenting? Mayo Clin Proc. 2009;84(4):362-8. https://doi.org/10.1016/S0025-6196(11)60546-6.

10. Hussain MA, Verma S, Gupta N, Al-Omran M. Carotid artery revascularization: What's the best strategy? Circulation. 2015;131(25):2226-31. https://doi.org/1 0.1161/CIRCULATIONAHA.114.013017.

11. Olechnowicz-Tietz S, Gluba A, Paradowska A, Banach M, Rysz J. The risk of atherosclerosis in patients with chronic kidney disease. Int Urol Nephrol. 2013;45(6):1605-12. https://doi.org/10.1007/s11255-013-0407-1.

12. Valdivielso JM, Rodriguez-Puyol D, Pascual J, Barrios C, Bermudez-Lopez M, Sanchez-Nino MD, et al. Atherosclerosis in chronic kidney disease: more, less, or just different? Arterioscler Thromb Vasc Biol. 2019:39(10):1938-66. https://doi.org/10.1161/ATVBAHA.119.312705.
13. Jashari F, Ibrahimi P, Nicoll R, Bajraktari G, Wester P, Henein MY. Coronary and carotid atherosclerosis: similarities and differences. Atherosclerosis. 2013; 227(2):193-200. https://doi.org/10.1016/j.atherosclerosis.2012.11.008.

14. von Reutern GM, Goertler MW, Bornstein NM, Del Sette M, Evans DH, Hetzel A, et al. Grading carotid stenosis using ultrasonic methods. Stroke. 2012; 43(3):916-21. https://doi.org/10.1161/STROKEAHA.111.636084.

15. Adams HP Jr, del Zoppo G, Alberts MJ, Bhatt DL, Brass L, Furlan A, et al. Guidelines for the early management of adults with ischemic stroke: a guideline from the American Heart Association/American Stroke Association Stroke Council, Clinical Cardiology Council, Cardiovascular Radiology and Intervention Council, and the Atherosclerotic Peripheral Vascular Disease and Quality of Care Outcomes in Research Interdisciplinary Working Groups: the American Academy of Neurology affirms the value of this guideline as an educational tool for neurologists. Stroke. 2007:38(5):1655-711.

16. Koga M, Kimura K, Minematsu K, Yamaguchi T. Diagnosis of internal carotid artery stenosis greater than $70 \%$ with power Doppler duplex sonography. AJNR Am J Neuroradiol. 2001;22(2):413-7.

17. Levey AS, Coresh J, Greene T, Stevens LA, Zhang YL, Hendriksen S, et al. Using standardized serum creatinine values in the modification of diet in renal disease study equation for estimating glomerular filtration rate. Ann Intern Med. 2006;145(4):247-54. https://doi.org/10.7326/0003-4819-145-4-2 00608150-00004.

18. Levey AS, Eckardt KU, Tsukamoto Y, Levin A, Coresh J, Rossert J, Zeeuw DDE, Hostetter TH, Lameire N, Eknoyan G. Definition and classification of chronic kidney disease: a position statement from kidney disease: improving global outcomes (KDIGO). Kidney Int. 2005;67(6):2089-100. https://doi.org/1 0.1111/j.1523-1755.2005.00365.x.

19. Ong KL, Cheung BM, Man YB, Lau CP, Lam KS. Prevalence, awareness, treatment, and control of hypertension among United States adults 19992004. Hypertension. 2007;49(1):69-75. https://doi.org/10.1161/01.HYP.00002 52676.46043 .18 .

20. Qureshi Al. Acute hypertensive response in patients with stroke: pathophysiology and management. Circulation. 2008;118(2):176-87. https://doi.org/10.1161/ CIRCULATIONAHA.107.723874.

21. American DA. 2. Classification and diagnosis of diabetes: standards of medical Care in Diabetes-2019. Diabetes Care. 2019;42(Suppl 1):S13-28. https://doi.org/10.2337/dc19-S002.

22. Bamford J, Sandercock P, Dennis M, Burn J, Warlow C. Classification and natural history of clinically identifiable subtypes of cerebral infarction. Lancet. 1991; 337(8756):1521-6. https://doi.org/10.1016/0140-6736(91)93206-O.

23. Quinn TJ, Dawson J, Walters MR, Lees KR. Reliability of the modified Rankin scale: a systematic review. Stroke. 2009;40(10):3393-5. https://doi.org/10.11 61/STROKEAHA.109.557256.

24. Habibzadeh F. Statistical data editing in scientific articles. J Korean Med Sci. 2017;32(7):1072-6. https://doi.org/10.3346/jkms.2017.32.7.1072.

25. Clark TG, Bradburn MJ, Love SB, Altman DG. Survival analysis part I: basic concepts and first analyses. Br J Cancer. 2003;89(2):232-8. https://doi.org/1 0.1038/sj.bjc.6601118.

26. Ford I, Bezlyak V, Stott DJ, Sattar N, Packard CJ, Perry I, Buckley BM, Jukema JW, de Craen AJ, Westendorp RG, Shepherd J. Reduced glomerular filtration rate and its association with clinical outcome in older patients at risk of vascular events: secondary analysis. PLoS Med. 2009;6(1):e16. https://doi. org/10.1371/journal.pmed.1000016.

27. Wen CP, Cheng TY, Tsai MK, Chang YC, Chan HT, Tsai SP, et al. All-cause mortality attributable to chronic kidney disease: a prospective cohort study based on 462293 adults in Taiwan. Lancet. 2008;371(9631):2173-82. https:// doi.org/10.1016/S0140-6736(08)60952-6.

28. Kelly DM, Rothwell PM. Prevention and treatment of stroke in patients with chronic kidney disease: an overview of evidence and current guidelines. Kidney Int. 2020;97(2):266-78. https://doi.org/10.1016/j.kint.2019.09.024.

29. Syed-Ahmed M, Narayanan M. Immune dysfunction and risk of infection in chronic kidney disease. Adv Chronic Kidney Dis. 2019;26(1):8-15. https://doi. org/10.1053/j.ackd.2019.01.004.

30. Subbiah AK, Chhabra YK, Mahajan S. Cardiovascular disease in patients with chronic kidney disease: a neglected subgroup. Heart Asia. 2016;8(2):56-61. https://doi.org/10.1136/heartasia-2016-010809.

31. Mallappallil M, Friedman EA, Delano BG, McFarlane SI, Salifu MO. Chronic kidney disease in the elderly: evaluation and management. Clin Pract (Lond). 2014;11(5):525-35. https://doi.org/10.2217/cpr.14.46.

32. Tedla FM, Brar A, Browne R, Brown C. Hypertension in chronic kidney disease: navigating the evidence. Int J Hypertens. 2011;2011:132405. 
33. Alicic RZ, Rooney MT, Tuttle KR. Diabetic kidney disease: challenges, Progress, and possibilities. Clin J Am Soc Nephrol. 2017;12(12):2032-45. https://doi.org/10.2215/CJN.11491116.

34. Singh JA, Cleveland JD. Gout is associated with a higher risk of chronic renal disease in older adults: a retrospective cohort study of U.S. Medicare population. BMC Nephrol. 2019;20(1):93.

35. Go AS, Chertow GM, Fan D, McCulloch CE, Hsu CY. Chronic kidney disease and the risks of death, cardiovascular events, and hospitalization. N Engl J Med. 2004;351(13):1296-305. https://doi.org/10.1056/NEJMoa041031.

36. Babitt JL, Lin HY. Mechanisms of anemia in CKD. J Am Soc Nephrol. 2012; 23(10):1631-4. https://doi.org/10.1681/ASN.2011111078.

37. Al-Dasuqi K, Payabvash S, Torres-Flores GA, Strander SM, Nguyen CK, Peshwe KU, et al. Effects of collateral status on infarct distribution following endovascular therapy in large vessel occlusion stroke. Stroke. 2020;51(9): e193-202. https://doi.org/10.1161/STROKEAHA.120.029892.

\section{Publisher's Note}

Springer Nature remains neutral with regard to jurisdictional claims in published maps and institutional affiliations.

Ready to submit your research? Choose BMC and benefit from:

- fast, convenient online submission

- thorough peer review by experienced researchers in your field

- rapid publication on acceptance

- support for research data, including large and complex data types

- gold Open Access which fosters wider collaboration and increased citations

- maximum visibility for your research: over $100 \mathrm{M}$ website views per year

At BMC, research is always in progress.

Learn more biomedcentral.com/submissions 